\section{Summary of: Pharmacy counter assistants and oral health promotion: an exploratory study}

\author{
B. J. Steel ${ }^{1}$ and C. Wharton ${ }^{2}$ \\ VERIFIABLE CPD PAPER
}

\section{FULL PAPER DETAILS}

${ }_{1 *}$ General Dental Practitioner and Medical Student,

Hull; ${ }^{2}$ Community Pharmacist, Whitley Bay,

Tyne and Wear

*Correspondence to: Dr Ben Steel

Email:b_steel_1_the@yahoo.co.uk

Online article number E19

Refereed Paper - accepted 24 July 2011

DOI: $10.1038 /$ sj.bdj.2011.938

${ }^{\circ}$ British Dental Journal 2011; 211: E19

Background The involvement of community pharmacists in oral health promotion is being increasingly recognised and studied. However, a large proportion of interactions in community pharmacies take place with pharmacy counter assistants rather than the pharmacist, and the role of pharmacy counter assistants in oral health promotion has received little or no attention until now. Aims To clarify the current state of affairs on pharmacy counter assistants' involvement with oral health promotion. Design and methods A postal-questionnaire-based survey of pharmacy counter assistants across East Yorkshire, North Lincolnshire and the Doncaster area. One hundred addresses were included and 35 responses were received. Results Pharmacy counter assistants are infrequently approached by the public for advice on matters of oral health and advice is not often volunteered despite a reasonable knowledge of the subject. Respondents identified a role for themselves in educating patients/customers, which they are keen to expand. Conclusions The expansion of the pharmacy counter assistant's role in oral health promotion would be of value to patients/customers. This should include increased opportunistic education and a more integrated position of pharmacy within a holistic health promotion strategy.

\section{EDITOR'S SUMMARY}

We have at our disposal thousands, tens if not hundreds of thousands of potential oral health educators whose contributions are currently ignored, overlooked or dismissed. Teachers form one cadre, journalists another and this paper identifies pharmacy counter assistants as a further body of willing recruits to the battle for improving oral health.

It is difficult to know whether the relative lack of inter-disciplinary cohesion on oral health matters and the individual knowledge of professional and healthcare personnel are due to shortcomings on the part of the dental profession or a reluctance to embrace this by those involved in various areas of healthcare. Certainly any success is severely limited in the case of our medical colleagues, whose often woeful lack of knowledge of dental issues comes to the fore in cases of emergencies in particular.

The possibility of utilising the services of what turns out to be a willing group of people in the form of pharmacy assistants, as outlined in this study, provides an interesting example of bringing into the fold a potentially valuable set of front-line advocates for oral health. How often do we hear that patients ask advice of others before consulting a professional because they did not want to be a bother or a nuisance? The ready availability of a pharmacy assistant to be able to quite literally offer 'over-the-counter' advice is a possible source of great value both to the enquirer as well as to the greater good of improved accurate knowledge and oral health.

How far this might be possible in terms of organisation, training and resources is quite another question but the authors should be commended for identifying what could in due course become a further asset in public dental health. One never knows how raising awareness of an issue might lead others to take up the cause and create effective pathways to achieving positive educational outcomes. Our own attitude as a profession to utilising the enthusiasm of groups within the healthcare environment should also lead to improvements for our patients which we should applaud; how great is the value of influence when we are not even in the room?

The full paper can be accessed from the $B D J$ website (www.bdj.co.uk), under 'Research' in the table of contents for Volume 211 issue 9.

Stephen Hancocks Editor-in-Chief

DOI: 10.1038/sj.bdj.2011.911 
TO ACCESS THE BDJ WEBSITE TO READ THE FULL PAPER:

- BDA Members should go to www.bda.org.

- Click the 'login' button on the right-hand side and enter your BDA login details.

- Once you have logged in click the 'BDJ' tab to transfer to the BDJ website with full access.

IF YOUR LOGIN DETAILS DO NOT WORK:

- Get a password reminder: go to www.bda.org, click the login button on the right-hand side and then click the forgotten password link.

- Use a recommended browser: we recommend Microsoft Internet Explorer or Mozilla Firefox.

- Ensure that the security settings on your browser are set to recommended levels.

IF YOU HAVE NOT YET SIGNED UP TO USE THE BDA WEBSITE:

- Go to www.bda.org/getstarted for information on how to start using the BDA website.
IN BRIEF

- Community pharmacies can play an important role in oral health promotion.

- Pharmacy counter assistants see a large number of patients/customers so could play a large part in this.

- Currently the potential of pharmacies in this regard is under-utilised.

- Many possible ways exist to increase the role community pharmacies, and specifically pharmacy counter assistants, play in oral health promotion.

\section{COMMENTARY}

The role of the community pharmacist in promoting oral health is now widely acknowledged. ${ }^{1,2}$ However, this study is one of the first to explore the potential role of pharmacy counter assistants (PCAs) in community-based oral health promotion. PCAs play an integral role within the pharmacy environment and are often the first point of contact for the general public within community pharmacies. Consequently, as the authors suggest, they offer considerable scope for promoting oral health through a constructive process of appropriate information, advice, support and referral.

The findings from this research provide a valuable and timely insight into a number of the key areas, including the nature and extent of requests for oral health information (most notably smoking cessation) and participants' levels of knowledge and understanding regarding oral health. The evidence suggests that, amongst this sample group, levels of understanding were variable, but generally reasonable. It is therefore important to identify training and support needs to ensure that PCAs are adequately equipped to offer appropriate oral health advice and to recognise when they may need to refer on to the pharmacist, general dental practitioner (GDP) or other health professionals.

Given the nature and size of the sample group, caution must of course be placed on generalising the findings. However, there does appear to be a desire, amongst these participants, to expand their role in relation to oral health promotion. PCAs may also therefore be best placed to offer opportunistic oral health advice, due to their 'front of shop role'. Further research is required in this area, particularly in relation to exploring the acceptability and effectiveness of PCA involvement in oral health promotion, but this study provides a good platform for further related research that could help to inform practice and policy.

P. Gill

Post Graduate Research Training Coordinator, Faculty of Health, Sport and Science, University of Glamorgan

1. Department of Health. Choosing better oral health: a better oral health plan for England. London: Department of Health, 2005

2. Pharmaceutical Services Negotiating Committee, National Pharmaceutical Association, Royal Pharmaceutical Society of Great Britain, Pharmacy Health Link. Public health: a practical guide for community pharmacists. London: National Pharmaceutical Association, 2004

\section{AUTHOR QUESTIONS AND ANSWERS}

1. Why did you undertake this research? Previous studies have shown that pharmacists in the community are approached by the public for advice on oral health matters, and that such advice is frequently given by pharmacists. However, we were mindful of the fact that a large proportion of patient/customer contacts in a community pharmacy occur with a pharmacy counter assistant rather than a pharmacist. No research has previously been done regarding their role on oral health education. Therefore we felt this important line of enquiry ought to be investigated, firstly to find out what is going on currently, then to explore ways in which their contribution could be increased and more integrated within oral health promotion as a whole.

\section{What would you like to do next in this} area to follow on from this work?

Having demonstrated the opportunity, ability and desire of pharmacy counter assistants to give oral health advice in community pharmacies, we feel the next step would be to confirm our findings in a more robust, prospective way across a larger sample size. As well as this further research is needed to explore the logistical and financial practicalities and patient acceptance of the advice given. If the results of these pieces of further research are favourable, a pilot could be conducted whereby pharmacies provide oral health advice in a more formal organised manner, as well as development of oral health-related CPD courses for pharmacy staff. 